\title{
En busca de respeto. Vendiendo crack en Harlem ${ }^{*}$
}

\author{
Philippe Bourgois
}

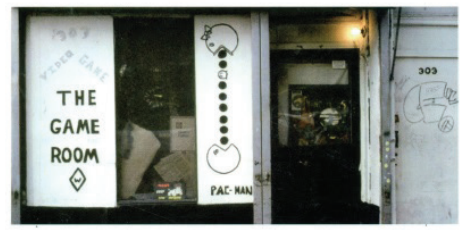

\section{EN BUSCA \\ DE RESPETO}

vendiendo crack en harlem

philippe bourgois

We siglo veintiuno

\section{Leonardo Piña C.}

\section{Cariño por el campo, o la etnografía en búsqueda de respeto ${ }^{1}$}

En principio, estos comentarios se pretendían como una discusión en torno a la ética y política de las decisiones etnográficas. Titulados de ese modo, y relevando algunos de los nudos con que nuestro invitado

* 2003. Buenos Aires: Siglo XXI Editores

** Departamento de Antropología, Universidad Alberto Hurtado. E-mail: Ipina@uahurtado.cl

1 Reseña presentada el día 5 de mayo de 2015, a propósito de la Conferencia magistral "La furia en el ghettto estadounidense. Segregación, expulsión y violencia en la ciudad contemporánea”, dictada por el Dr. Philippe Bourgois en la Universidad Alberto Hurtado, Santiago de Chile, en el marco de la visita de cooperación internacional (Fondecyt 11140871). 
resuelve esa relación en su etnografía más conocida, su afán era ahondar en nuestras propias prácticas disciplinarias, ya sea en el campo o en su representación, de forma tal que En busca de respeto (Bourgois 2003), más que un cristal de crack que se fuma y del que eventualmente se puede hablar, lo fuese como espejo de lo que hacemos o hemos dejado de hacer. Atendiendo a ello, y haciendo el registro de las anotaciones que desde lo ético permitían apreciar la dimensión política de su posicionamiento investigativo, la magnitud y alcances de su etnografía la fueron señalando como una empresa, si bien plausible en nuestros horizontes, atractiva al punto de la novedad e incluso la sorpresa. Desde entonces son lo que son, una pregunta por el lugar de la etnografía en nuestra antropología.

\section{Uno. Etnografía y antropología.}

“¿Por qué después de la prolongada estancia de Malinowski en las islas Trobriand -se preguntan Michel y Françoise Panoff, en un artículo bastante en desuso ya- el etnólogo todavía debe ir personalmente al campo, y no puede contentarse con interpretar hechos de segunda mano?" (1975: 79). ¿Por qué -insisten-, habría de "abandonar el ejemplo, tan brillantemente ilustrado, no tanto por Frazer como por Durkheim y Mauss, de una etnología construida en cámara?" (ibid). ¿Acaso -vuelven sobre el tema- "compartir la vida de los 'salvajes', no es solo una novatada de iniciación impuesta a los más jóvenes y de la que los mayores pueden pasarse, tal como es posible librarse de la obligación de ir a la clase de gimnasia, con la presentación de un certificado médico? ¿El trabajo de campo -rematan siempre con forma de pregunta- no está solo destinado a los debutantes? Y el investigador con galones, ¿no debiera dejarlo para dedicarse a actividades más propiamente científicas?" (ibid).

"Me metí en el crack en contra de mi voluntad", por su parte escribe Philippe Bourgois, varios años después (2003: 31). Y relatando que llega a East Harlem en la primavera de 1985, buscando "un departamento económico en Nueva York donde pudiera escribir un libro sobre la experiencia de la pobreza y la marginación étnica en el corazón de una de las ciudades más caras del mundo" (ibid), abre las páginas de una de las etnografías más completas que se hayan escrito sobre la materia, cruda e inusualmente amable al mismo tiempo. Manual, casi, acerca de cómo hacer trabajo de campo en nuestras propias ciudades, su no proyectado afán en tales términos lo sitúan, muy probablemente, entre los libros 
más leídos de nuestra disciplina y a su autor, bien podría decirse así, en una suerte de refundador del género en tiempos en que éste, el género antropológico, pareciera no necesitar de tal refundación.

¿Por qué, entonces, tal afirmación?

"Desde una perspectiva teórica -explicita unas líneas más adelante- me interesaba examinar la economía política de la cultura callejera en la inner city. Desde una perspectiva personal y política -vuelve a sincerardeseaba investigar el talón de Aquiles de la nación industrializada más rica del mundo, y documentar la manera en que les impone la segregación étnica y la marginación económica a tantos de sus ciudadanos afronorteamericanos y latinos" (ibid). De paso, y entroncando con la pregunta que precede, su esfuerzo de campo queda inscrito en un vaivén comprensivo que se mueve entre la riqueza del dato etnográfico, que intenta conocer, y su lectura a distinta escala, en sus propias palabras el "debate teórico acerca del rango de acción de las personas versus la estructura social, es decir, la relación entre la responsabilidad individual y las restricciones sociales estructurales" (op cit: 47).

Más que atractivo, por supuesto, pero de la refundación antes dicha, nada todavía.

\section{Dos. La carpa en la aldea.}

"Las técnicas etnográficas de observación participante -en clave metodológica, precisa en otra parte nuestro invitado-, desarrolladas sobre todo por la antropología social desde los años veinte, han demostrado ser más adecuadas que las metodologías cuantitativas para documentar la vida de los individuos marginados por una sociedad hostil. Solamente tras establecer lazos de confianza -continúa-, proceso que requiere mucho tiempo, es posible hacer preguntas incisivas con respecto a temas personales y esperar respuestas serias y reflexivas. Por lo general -agrega-, los etnógrafos viven en las comunidades que estudian y cultivan vínculos estrechos de larga duración con las personas que describen. Para reunir 'datos precisos', los etnógrafos violan los cánones de la investigación positivista. Nos involucramos de manera íntima con las personas que estudiamos" (op cit: 43). Y para hacerlo, como él mismo dice y efectivamente realiza, el trabajo de campo de largo aliento, tipo carpa en la aldea, parece esencial y decididamente significativo. Veamos por qué: 
Con esta meta en mente, amanecí en la calle y en las casas de crack en cientos de oportunidades, para poder observar a los adictos y a los traficantes que protagonizan este libro. Por lo general, utilicé un grabador para documentar sus conversaciones e historias personales. Visité a sus familias para participar en sus fiestas y reuniones íntimas, desde la cena de Acción de Gracias hasta el Año Nuevo. Pude entrevistarme, y en muchos casos entablé amistad, con las esposas, amantes, hermanos, madres, abuelas y, cuando fue posible, con los padres y padrastros de los vendedores de crack que aparecen en estas páginas. También dediqué tiempo a entrevistar a los políticos locales y a asistir a las reuniones de las instituciones comunales (ibid).

¿La duración del trabajo? Cinco años de tiempo calendario, hacia la segunda mitad de la década de los ochenta y comienzos de los noventa; tres en tiempo real durante ese lapso; mucho más si se consideran las relaciones de continuidad que, desde entonces, ha mantenido con varios de los protagonistas de su libro.

¿El lugar? El Barrio, como se llama a East Harlem en Nueva York, en un edificio, junto a su mujer y su hijo, a dos puertas de distancia del Salón de Juegos, sitio de reunión, tráfico y consumo de crack, y otras sustancias tales como la heroína y cocaína, muy usadas por entonces.

\section{Tres. La antropología.}

Contrario a la vocación, riqueza y magnitud etnográfica que acá se comenta, o complementario a ellas más bien, en otra parte de su trabajo el mismo autor advierte:

La historia reciente del crack y de la cocaína inyectada en los Estados Unidos y en Canadá nos enfrenta al hecho de lo poco que comprendemos el fenómeno del abuso de determinadas sustancias desde una perspectiva macrosociológica o antropológica. No hemos elaborado una teoría coherente y útil que ofrezca las explicaciones más básicas sobre el quién, cuándo y porqué de las drogas. Necesitamos vincular los patrones de preferencias por las drogas y los grados de adicción a las mismas a las grandes fuerzas estructurales históricas que crean grupos sociales vulnerables, y hemos de documentar las consecuencias no pretendidas de las políticas disfuncionales del sector público y de las instituciones gubernamentales que agravan los daños provocados por las drogas (2004: 95).

¿Se aleja de ese otro afán entonces? ¿Lo hace cuando la crudeza de la experiencia que conoce lo lleva a intentar comprenderla más allá de su misma singularidad? ¿Es aplastada aquella densidad cuando procura leerla a la luz de las dinámicas de contracción o expansión económica, de la mano de las políticas de seguridad social, o documentando y 
tratando de estimar los efectos que en la vida cotidiana podrían tener los procesos de precarización del empleo, segregación del espacio o encarcelación de la pobreza? ¿Ayuda, por otra parte, a la mantención de los estereotipos cuando, aparejado de ese mismo impulso, enfrenta los problemas que su representación suponen en materia de escritura o descripción de lo que observa?

"Cualquier examen detallado de la marginación social enfrenta serias dificultades con respecto a la política de la representación" (2003: 41), al respecto dice este etnógrafo. "Me niego a omitir o minimizar la miseria social de la que he sido testigo por temor a que una imagen desfavorable de los pobres se perciba como incómoda o "políticamente incómoda', pues eso me haría cómplice de la opresión" (op cit: 42), agrega, desmarcándose de esa connivencia que critica. "Es por lo tanto lógico -señala, haciendo una opción que en ningún caso es solo éticaque este libro encare las contradicciones inherentes a la representación de la marginación social en los Estados Unidos mediante la exposición de los acontecimientos brutales sin censura, tal como los experimenté o como me los relataron quienes participaron en ellos" (ibid).

Y alejándose de lo que considera una práctica mayoritaria ("la mayoría de los etnógrafos producen análisis comprensivos desprovistos de toda mirada crítica hacia los grupos y culturas que estudian", op cit: p. 45), explica:

Históricamente, los etnógrafos han evitado abordar temas tabúes como la violencia personal, el abuso sexual, la adicción, la alienación y la autodestrucción. Parte del problema surge a raíz de uno de los paradigmas de la antropología funcionalista, que impone orden y comunidad en sus proyectos de estudio. Por otro lado, la observación participante requiere de la injerencia personal de los etnógrafos en las circunstancias investigadas, lo que a menudo los incita a omitir las dinámicas negativas porque deben establecer lazos de empatía con las personas que estudian y necesitan su autorización para vivir con ellas. Esto puede conducir a diversas formas de autocensura que acaban afectando las cuestiones y los entornos examinados (op cit: 44).

\section{Cuatro. Solo es nuevo lo que se ha olvidado.}

Viejo fórmula adjudicada a una de las costureras de María Antonieta, su inclusión acá dice relación con la importancia de la etnografía y su reposicionamiento en tiempos que no lo hacen parecer necesario. La novedad, sin embargo, que su lectura despierta algo dice en la otra 
dirección. Nuestras prácticas investigativas, tributarias cada vez más de la entrevista en cualquiera de sus formatos, y cada vez menos de la observación participante y el trabajo de campo de largo aliento, también. Nuestras propias responsabilidades 0 dependencias laborales, el hecho de que la investigación sea privativa de unos pocos, sea cara de solventar, cuente con escasas fuentes de financiamiento y no pueda romper, en términos concretos, los tiempos de realización que marcan esos otros compromisos, lo refuerza aún más.
No todos somos Bourgois, es cierto, ni tenemos por qué serlo (o podremos acceder a esas fuentes de financiamiento), pero el cariño por el campo, la búsqueda creativa de otras modalidades de trabajo, la responsabilidad y el aprovechamiento de los espacios de formación en que ello puede darse, señalan un montón de posibilidades. La observación de la mucha diversidad que esconden nuestras ciudades, y el trabajo comprometido y crítico, evidencia y sistematización en mano, podrían hacer la diferencia.

\section{Bibliografía}

Bourgois, Philippe. 2003. En busca de respeto. Vendiendo crack en Harlem. Buenos Aires: Siglo XXI Editores.

Bourgois, Philippe. 2004. "Crack-cocaína y economía política del sufrimiento social en Norteamérica”.
Humanitas 5: 95-103.<http://www.fundacionmhm.org/ Mono5/Articulos/edicion12.html> Consultado 26/07/07.

Panoff, Michel y Panoff, François. 1975. “¿Para qué sirve la etnografía?". La antropología como ciencia. Llobera, Josep (Comp.). Barcelona: Anagrama. 79-83. 